\title{
JONATHAS ABBOTT: INDIVIDUALIDADE E COLECIONISMO NA BAHIA NO SÉCULO XIX
}

\begin{abstract}
Mais que um dos "Ingleses no Brasil", o jovem Jonathas percorreu o itinerário dos verdadeiros imigrantes que queimam nos navios e reinventam uma nova identidade nacional na terra de adoção [...] o jovem imigrante passou por um drástico processo de abrasileiramento, não só formal e jurídico, que incluiu a sua adoção ao catolicismo, e sua naturalização, também de alma, gostos e costumes, melhor seria dizer que ele se abaianou por completo [...] culminando por ter gosto de frequentação e nos prazeres, hoje misteriosos para nós, do doce convívio com damas recolhidas em conventos. [...] A Bahia foi lugar de ascensão social e de realizações profissionais e culturais do antigo e humilde groom de 1812 (Galvão, 2007: 10).
\end{abstract}

O contexto histórico da formação da coleção Jonathas Abbott do Museu de Artes da Bahia, a mais importante da instituição, é tão pouco conhecido quanto a vida do colecionador Jonathas Abbott, inglês que imigrou para o Brasil em I8I2, permanecendo no país até sua morte em I868. Com o objetivo de relacionar a construção da individualidade de Abbott com a essência estética da coleção e a natureza do gosto do imigrante inglês, utilizamos como fonte de pesquisa o Diário de viagem do colecionador à Europa de I830 a I832 (ver Galvão, 2007). ${ }^{\text {I }}$

A expressão do gosto e a essência estética da coleção fazem parte do que Erwin Panofsky (I99I) denomina "cosmos da cultura": registros humanos que expressam a variedade da cultura. Os elementos conformadores do espírito da Galeria Abbott - sua coleção - nos conduzem à expressão de uma in- 
tenção subjetiva e objetiva² de um projeto, de um princípio e de uma razão de ser que relaciona a formação da coleção à construção da individualidade de Abbott: jovem que chega à Bahia como um imigrante pobre e, por meio de um investimento em seu capital cultural e econômico, ${ }^{3}$ passa a ocupar um lugar social de destaque na sociedade baiana da segunda metade do século XIX.

Ao se eleger seu Diário de viagem como fonte de pesquisa para uma discussão da formação de sua individualidade apoiada em um sentido estético e um gosto, entende-se que os fatos estéticos e biográficos se definem como deslocamentos e colocações do indivíduo no espaço social. Em "A ilusão biográfica", Pierre Bourdieu (I996: 52) diz que "[...] em se tratando da análise da trajetória do indivíduo, não podemos compreendê-la sem que tenhamos previamente construído os estados sucessivos no campo no qual ela se desenrolou". A trajetória de Abbott e a formação de sua coleção são registros de seu Diário. Os dois processos formativos encarnam as manifestações da individualidade de Abbott em diferentes tempos, constituindo a expressão de uma intenção subjetiva e objetiva de um projeto maior de vida, pois é a partir de seu relato biográfico - o Diário - que encontraremos um sentido, extrairemos uma lógica, ou, ainda, uma consistência no conjunto de suas escolhas. ${ }^{4}$

O Diário de viagem de Abbott é tomado aqui como parte de uma tradição literária que começa a se desenvolver na Europa nos primórdios do século XVIII e tinha por objetivo escrutinar culturas exóticas ou, simplesmente, viajar por amor à arte e à cultura da Antiguidade Clássica. Esta literatura teve como característica principal uma narrativa descritiva, impessoal, centrada no relato de elementos pitorescos e, em sua maioria, era praticada por jovens da aristocracia inglesa. No século XIX, estende-se aos filhos da burguesia europeia, os quais buscavam o conhecimento artístico, arqueológico ou científico - fora ou dentro do continente europeu - e, então, ganha contornos mais imaginativos, com seus autores passando a relatar as emoções e os sentimentos pessoais que a visita aos lugares escolhidos lhes suscitava (Boyer, I998). Esta prática social do viajar pelo puro prazer e amor à arte e à cultura da Antiguidade (Salgueiro, 2002: 30I) ficou conhecida como Grand Tour. Em seu Diário, Abbott nos apresenta um relato minucioso e emocional sobre o seu Grand Tour pela Itália entre I830 e I832.

Devemos sublinhar que Jonathas Abbott, no conjunto dos viajantes europeus, foi uma exceção. Em primeiro lugar, realiza seu Grand Tour não por ser aristocrata ou filho da aristocracia ou da alta burguesia europeia, mas por ser um imigrante que, por meio do trabalho, proporciona a si uma viagem à Europa que inclui um Grand Tour e uma especialização de seus estudos em medicina em Paris - profissão escolhida por ele no Novo Mundo. Em segundo lugar, ao contrário de narrar um encontro com o exótico, Abbott narra suas impressões sobre a Europa para leitoras brasileiras - especialmente as senhoras baianas por ele denominadas "doces amigas recolhidas das Mercês". Ou 
seja: a relação com as mulheres que fizeram parte de sua vida exerceram papel importante na construção de sua individualidade, bem como na de suas escolhas, como colecionador.

Ao contrário dos demais viajantes ingleses que aqui aportaram no século XIX, seu olhar foi o do Sul para o Norte, ou seja, olhar onde o Brasil é apenas o pano de fundo. É nesse sentido que para apreender a excepcionalidade do escrito, não podemos perder de vista quem o escrevia, sua personalidade e sua circunstância, o meio de onde saiu e aquele ao qual passou a pertencer, as ambições de carreira que o moviam, juntamente com o desejo de amor e afeto. Por meio da leitura de seu Diário, podemos perceber seu humor, seu pragmatismo, seu senso do concreto, a admiração pelas primeiras transformações modernizadas levadas pela Revolução Industrial em sua velha Albion (modo como se referia à sua Inglaterra natal [Galvão, 2007]), bem como o encontro que teve com parte do Mundo Clássico ${ }^{5}$ - episódio deflagrador de seu desejo de formar uma coleção de artes.

\section{JONATHAS ABBOTT NA BAHIA: O ENCONTRO COM A ARTE, OS AMORES E A FORMAÇÃO EM MEDICINA}

Foi entre agosto e outubro de I8I 2 que desembarcou em Salvador, Bahia, um jovem que acabara de completar 16 anos: vinha de Londres, Inglaterra, e seu nome era Jonathas Abbott. Nascera em Kennington, distrito de Lambeth, região muito empobrecida de Londres, burgo da classe trabalhadora, fora dos limites da cidade. Seu pai, John Abbott, era marceneiro e casado com Sarah Abbott, com quem teve seis filhos. Por tradição oral, sabe-se que Jonathas veio para o Brasil na condição de groom (cavalariço) do médico luso-baiano José Álvarez do Amaral, que, pela Carta Régia de 29 de dezembro de I8I5, fora nomeado secretário do Colégio Médico-Cirúrgico da Bahia. No entanto, não temos informações de como os dois se conheceram. O que podemos afirmar é que Jonathas Abbott nasceu em I796, no fim da Era Georgiana, período conhecido como Regência (I7I4-I830), cuja divisão e hierarquia de classes sociais estavam claramente definidas, tornando extremamente difícil a ascensão social das classes pobres e trabalhadoras na Inglaterra. Uma das suposições levantadas neste texto é de que sua situação social no país de origem tenha sido uma das razões que o levaram a deixar a Inglaterra para reconstruir a vida no Novo Mundo como imigrante.

A princípio, em Salvador, suas ocupações giraram em torno dos estudos em latim, no convento dos monges da Ordem Terceira de São Francisco. Com os franciscanos, Jonathas teve acesso ao estudo da arte clássica, pois o Convento de São Francisco, segundo a historiadora da arte baiana Maria Helena Ochi Flexor (s/d), ministrava o ensino artístico, paralelamente aos ateliês, às tendas e às oficinas dos mestres, onde eram confeccionados painéis, tetos, 
estandartes, andores e charolas. Em I828, criou-se, no Convento de São Francisco, uma cadeira de desenho, com aulas dadas pelo pintor Franco Velasco, ${ }^{6}$ da Escola Baiana de Pintura. Embora ministrada no convento, tinha caráter público. A nosso ver, o estreito contato com os franciscanos e com os artistas da Escola Baiana de Pintura fez emergir um gosto, um senso estético, o qual se evidenciou na compra da primeira peça da pinacoteca de Abbott - adquirida em Palermo em I830: uma cópia da tela do pintor renascentista Correggio, de temática religiosa, nominada, "Cabeça de Cristo agonizando".

Aos 20 anos Abbott já era professor de latim. As aulas transformaram-se em sua principal fonte de renda, possibilitando-lhe sustentar a família que constituiu. Em I8I8, ainda cursando medicina, casou-se com Hermelinda Máxima Coelho, filha de portugueses e sua vizinha, na Ladeira da Preguiça, na freguesia da Conceição da Praia, localizada na Cidade Baixa. A Ladeira da Preguiça era local onde viviam ex-escravos, homens pobres livres, incluindo neste contingente os imigrantes portugueses, que trabalhavam como pequenos comerciantes e aumentavam sua renda mantendo escravos de ganho. Hermelinda, portanto, era filha de imigrantes que, assim como Abbott, buscavam uma vida melhor nas terras brasileiras. Com ela, Jonathas teve dois filhos, que vieram a falecer, bem como Hermelinda, que faleceu em I828.

Ainda casado, por volta de I824, Jonathas inicia uma relação paralela durante aproximadamente cinco anos com uma viúva argentina de ascendência inglesa: Ana Cecilia Walters, com quem teve mais dois filhos, Cecília Ana e Jônatas, nascidos entre I824 e I826. Em I828, ambos foram perfilhados por Jonathas após a morte de Hermelinda, deixando descendência até os dias atuais. Ana Cecilia conheceu Jonathas na Bahia e com ele viveu uma história de amor por alguns anos. Partiu para o Rio de Janeiro em I830, por exigência de seu pai, que não suportava ver a situação ilegal da filha com Jonathas. Ela viaja para o Rio de Janeiro no mesmo ano em que Jonathas vai para a Europa. Portanto, não se casaram, o que deixa claro que Jonathas preferiu investir nos estudos, especialmente em seu doutoramento na Europa, em detrimento de uma condição conjugal estabilizada. Contudo, após seu retorno da Europa, em I832, Jonathas levou os dois filhos que tivera com Cecilia para viver consigo, dando-lhes educação, carinho e amor. Percebemos, assim, que tanto Hermelinda quanto Cecilia despertavam em Jonathas sentimentos de profundo afeto e amizade e foram mulheres que o auxiliaram na trajetória profissional, na busca por um novo espaço social e pelo conhecimento, e Cecilia, em especial, despertou no jovem grande paixão.

Além de Hermelinda e Cecilia, Jonathas foi também um freirático, ou seja, mantinha relações de amizade com senhoras recolhidas em conventos, as quais não tinham necessariamente vocação religiosa. Para as mulheres, essa condição era uma das alternativas para senhoritas ou senhoras das classes abastadas que não se casavam ou que enviuvavam, mas tinham acesso a 
uma educação escolar. Jonathas tinha seu coração incendiado pelas "doces amigas do Convento das Mercês", em Salvador, e sobre elas escrevia em seu Diário (Galvão, 2007: 98): “[...] mostram-me essas senhoras uma amizade que me enche de prazer. Uma delas já me deu provas de um sentimento ainda mais doce [...]."

A prática do freiratismo, segundo João Adolfo Hansen (2003: 68-85), foi muito comum em Portugal, desde a Idade Média, e no Brasil colonial, especialmente na Bahia. Jonathas escreve seu Diário para elas, pois desejava que seus relatos causassem furor em suas "doces amigas recolhidas", como ele costumava chamá-las. Acreditava que, ao lerem seus relatos sobre o encontro com objetos religiosos que coletou na Europa, além de suas visitas a catedrais, museus e cidades históricas, se sentiriam entusiasmadas, delirantes e curiosas. Ao suspirar por essas senhoras em seu Diário, percebemos o desejo de Abbott em compartilhar com elas seu sentimento de êxtase ao olhar, tocar e sentir o aroma de terras que um dia pertenceram a culturas tão representativas em sua concepção de mundo e na dessas senhoras. Podemos suspeitar, então, que elas pertenciam a uma classe de mulheres que despertam no homem os prazeres do conhecimento, ao mesmo tempo em que impossibilitam a realização integral do desejo sexual. Por outro lado, podemos inferir também que essa forma de afeto talvez fosse para Abbott a mais apropriada à época, já que seu desejo maior era investir na obtenção de conhecimentos - científico e artístico.

Segundo Ana Miranda, em Que seja em segredo... (1998: 52), obra que analisa a prática epistolar entre cavalheiros mundanos e damas portuguesas, religiosas ou não, que viviam em conventos em Portugal no século XVII, "houve um tempo em que o desejo sexual transpôs os limites da espiritualidade reclusa [...]. Para isso, nada como buscar o prazer na escuridão das celas do convento". Ao longo de sua viagem à Europa, Jonathas refere-se inúmeras vezes, a D. Maria Cândida e a D. Maria Margarida (ambas recolhidas nas Mercês), escrevendo em seu Diário (Galvão, 2007: 457): "Sim, cara Margarida, de ti cuidei ouvir hoje a voz sonora: tu hoje me arrancaste suspiros de saudades e até lágrimas, mas eu ainda espero derramá-las de prazer". A impossibilidade de realizar o desejo sexual parecia ser compensada na obtenção de objetos-relíquias: os registros do passado na construção de seu presente.

Contudo, ao retornar da Europa, após ser recebido com muito entusiasmo pelas amigas recolhidas, decide deixar de vê-las, já que os encontros acabaram saindo de seu controle, pois passaram a tomar muito de seu tempo afetivo e concreto. Assim, aos 42 anos, contrai segundas núpcias com uma viúva de posses, três anos mais velha, D. Ana Joaquina de Freitas, em I838. Seguindo a trajetória de Jonathas, parece-nos que o rompimento com as "doces amigas recolhidas" e o casamento com D. Ana Joaquina fizeram parte de seu projeto de ascensão social. D. Ana Joaquina era viúva rica e tinha apenas 
um filho; já Jonathas estava em plena ascensão profissional, passando a ocupar lugar de destaque na sociedade baiana. Após o casamento, o patrimônio de Jonathas dobrou, o que lhe possibilitou adquirir muitas obras e objetos de arte e posição social de maior destaque.

Em I8ı6, Jonathas matriculou-se no Colégio Médico e iniciou seu curso de cirurgia. Parece-nos fora de dúvida a influência do Dr. José Álvarez do Amaral na decisão do jovem imigrante, pois, como patrão, ou amigo patrão, o provável é que já houvesse descoberto nele os dotes da inteligência, da energia e da disciplina que outros também notariam, como o 8응 Conde dos Arcos (D. Marcos de Noronha e Brito), que governou a Bahia entre I8Io e I8I8 e para quem Abbott trabalhou como tradutor de documentos diplomáticos do inglês para o português, tornando-se protegido do conde. Graduou-se em I820, e, em I82I, por ter frequentado mais um ano, foi aprovado com distinção, o que lhe deu a condição de cirurgião formado com o direito exercer medicina e cirurgia em todas as partes do Império. Assim, em março de I829, foi empossado na cátedra de anatomia da Escola de Medicina da Bahia. Logo começou a planejar uma viagem de especialização em Paris, bem como um doutoramento por uma tradicional e renomada universidade europeia. Esta prática se tornava comum entre um novo grupo de jovens profissionais baianos, recém-formados pela Escola de Medicina, mas não só entre eles, já que os artistas também começavam a viajar a Paris para aprender com os grandes mestres da pintura. Segundo Maria Helena Ochi Flexor (s/d: 2):

No século XIX, a Província da Bahia já enviava alguns artistas para se aperfeiçoar na Europa, independentemente de instituições oficiais ou particulares. Foram estudar em Paris Francisco Rodrigues Nunes, que ensinava desenho para estudar pintura; Francisco Moniz Barreto Filho, para estudar música e pintura e Francisco de Azevedo Monteiro Caminhoá para estudar arquitetura civil, entre outros. A França e a Itália eram os países preferidos.

É importante ressaltar que a escolha deste grupo de jovens, entre eles Jonathas, por uma viagem à Europa deixa perceber que, na primeira metade do século XIX, vai se diferenciando em Salvador um grupo de profissionais liberais, de intelectuais e artistas provenientes das classes média e alta, de atuação docente na maioria dos casos, que parte para completar seus estudos na Europa, especialmente em Paris. Estes homens da elite intelectual local tornaram-se destacados professores na cidade, com fortes inquietudes culturais, as quais se manifestariam, algum tempo depois, no interesse pela história, pela arte, pela música, pelas políticas local e nacional. Com o tempo, tais inquietudes se transformariam em práticas de diferenciação social de classe, passando as coleções de arte de valor diversificado, formadas por muitos deles, a fazer parte deste legado. Pois foram essas coleções que, posteriormente, formaram os atuais museus da Bahia. 
Seguindo esse fio analítico, verificamos que Jonathas Abbott participou, junto com outros de sua geração, de um momento peculiar da história da cidade, a saber, a criação de uma esfera cultural diferenciada plasmada pela fundação de várias instituições orientadas para difundir a história, a arte e a cultura, como as sociedades científicas, a fundação do Instituto Histórico e Geográfico Brasileiro e da Sociedade de Belas Artes (ambos em I856). Aliás, Jonathas participou de todas as associações e sociedades científicas, sendo a Sociedade de Belas Artes fundada em sua casa, no Caminho Novo do Gravatá, por um conjunto de homens das letras e das artes. Entre eles, destacam-se o Dr. Antônio José Alves (pai do poeta Castro Alves, colega de Jonathas na Congregação da Faculdade de Medicina e grande colecionador), o Dr. João José Barbosa de Oliveira (pai do senador Rui Barbosa, médico e seu amigo), o dramaturgo Agrário de Menezes, o poeta Muniz Barreto, Gaspar José Lisboa e o pintor baiano Rodrigues Nunes, sendo o próprio Jonathas Abbott o presidente da Sociedade.

\section{A IDA À EUROPA: O GRAND TOUR E OS ESTUDOS EM MEDICINA}

Em 20 de julho de I830, a bordo da galera sueca Ariadne, Jonathas parte para a Europa e lá permanece até I832. Em seu programa de viagem, o estudo da medicina moderna com grandes médicos, como Guillaume Dupuytren, no famoso hospital Hôtel Dieu, e o Grand Tour não só estavam intimamente relacionados, mas traduziam o desejo por conhecimento.

O "inglês pobre", como se referiu Gilberto Freyre (2000) a Jonathas, transformara-se, na Bahia, em um imigrante em ascensão que, por ter acesso à educação, construiu progressivamente um capital econômico e cultural que possibilitou alargar seus horizontes como indivíduo. Assim, Jonathas anota em seu Diário todas as experiências vividas na Europa, tanto no plano profissional quanto no afetivo. Mas é especialmente sugestivo quando sublinha, nestes dois anos, o contato com os fragmentos da Antiguidade Clássica, através de cacos de azulejos, esculturas, ruínas, cidades, paisagens geográficas, obras arquitetônicas, templos etc. - contato que o levou a refinar seu gosto, adquirindo objetos, os quais fariam parte de sua coleção, já que o levariam a recordar para sempre a Antiguidade do mundo ocidental.

Vemos, então, que Jonathas parte para a Europa com um programa bem-direcionado: estudar medicina e fazer seu Grand Tour - uma viagem por prazer e amor à cultura, buscando entrar em contato com a arte e cultura clássicas. Para além de um prazer pessoal, Jonathas financia sua viagem como estratégia de ascensão social e profissional, pois sabia que, ao retornar, se tornaria um homem respeitável na sociedade de Salvador. Portanto, o investimento na construção de sua individualidade objetiva e subjetiva tinha para ele enorme valor. Nesse aspecto, Jonathas considerava a viagem e os estudos bens simbólicos e marcadores privilegiados de classe. A viagem serviria como 
um instrumento de distinção, por excelência, já que ao se apoiar numa relação de proximidade com a arte e a ciência, resultaria em cultura objetiva e subjetiva, o que, por consequência, levaria à sua ascensão social (Bourdieu, 2008).

É nesse esquema de ascensão social que Jonathas investe também na construção de uma rede de relações que o tornaria um homem respeitável ao retornar a Salvador. Logo que chega a Paris, em 28 de outubro de I830, instala-se em um quarto mobiliado no hotel Saint Germain, na rue Sainte Marguerite, por 26 francos mensais. O tempo lá foi por ele judiciosamente repartido entre as lições dos grandes mestres da medicina e as visitas frequentes a museus de arte, coleções as mais variadas e idas a conferências sobre literatura francesa no Instituto de França, no Instituto de Ciências e também ao teatro - Jonathas foi exímio tradutor de Molière.

As horas vagas eram dirigidas à construção de relações com titulares da sociedade baiana, como Domingos Borges de Barros, o Visconde de Pedra Branca, pai de Luísa Margarida de Barros Portugal, futura Condessa de Barral, que, posteriormente, o indicaria como um dos médicos mais respeitáveis da Bahia quando D. Pedro II visitou esta província em I859.7 Ainda em Paris, fazia também visitas frequentes ao marquês de Resende e a Góes Calmon e passou a ter como companheiros estudantes de medicina, a maioria deles proveniente das classes abastadas da Bahia, os quais se tornaram seus amigos íntimos após seu retorno a Salvador.

\section{NA ITÁLIA: DOUTORAMENTO E COLECIONISMO}

Diminuído o ritmo de atividades escolares, no verão de I83i não havia muito que justificasse a presença de Abbott em Paris e ele toma uma diligência para Marselha. Dez dias depois, embarca num brigue francês até Palermo e em nove dias lá estava. Esquadrinhou Palermo e suas redondezas: as soberbas igrejas, com seus famosos mosaicos, sendo todas as visitas devidamente registradas em seu Diário. Protocola um documento ao rei de Palermo solicitando autorização para seu doutoramento. Enquanto aguardava a decisão continuou sua visita a Palermo. Em agosto, Jonathas Abbott estava aprovado nos exames de doutorado. Dois acontecimentos em Palermo foram decisivos para o início de sua famosa coleção: andando pela cidade, ele adquire a cópia de Correggio, a "Cabeça de Cristo agonizando", que vira na véspera na coleção da universidade. O segundo acontecimento foi sua partida para o Grand Tour na Itália, onde visitou várias cidades da Antiguidade Clássica, incluindo Pompeia, onde mitologia e arte apareciam em imagens oníricas (Galvão, 2007: 362): "Imagens de deusas, brincos de senhoras, máscaras de teatro, moedas, corpos carbonizados [...] os teatros cômico e trágico, de mármore, estão inteirinhos, tanto eram sólidas as obras da Antiguidade [...] visitei os templos das deusas Ísis, de Mercúrio, de Júpiter, de Esculápio e o de Vênus [...]”. 
Vai a Herculano e a Roma - sua grande paixão -, e também a Nápoles, a Resina, a Puzzuoli, à Toscana, à Licurgia. Além de visitas às cidades com seus monumentos, estátuas, galerias e museus, esquadrinha a geografia das regiões por onde passa: lagos, montanhas, vinhedos, o Vesúvio - para ele uma "eterna maravilha". Anota em seu Diário a compra de objetos que vão constituindo sua coleção (Galvão, 2007: 367): “[...] comprei vários objetos feitos das lavas do Vesúvio, e mesmo estampas, a fim de lembrar-me sempre dessa ignívoma montanha [...]". Passa a adquirir o conhecimento de um connaisseur, de um colecionador. Aos poucos, familiariza-se com as obras e os objetos que vê. Segundo Pierre Bourdieu (2008: 198) ser um connaisseur "é uma arte, um controle prático que, à semelhança de uma arte de pensar ou viver, só pode ser transmitida por contato repetido com obras culturais". Assim, Jonathas adquire vários objetos na viagem pela Itália, para ele, todos uma relíquia, um registro, uma "imagem lembrança”, conforme definiu Walter Benjamin (I987: 229): "[...] a peça recém-adquirida emerge como uma ilha no mar que envolveu seus sentidos".

No dia 29 de agosto de I83i, às Io horas da manhã, Abbott aponta em seu Diário (Galvão, 2007: 452): “[...] descobrimos a capital do mundo antigo, e hoje do mundo cristão, a grande e majestosa Roma. Senti não sei que prazer ao vê-la com os meus próprios olhos [...] avizinhar-me a uma cidade cujo nome só basta para encher de admiração e respeito".

Para Abbott, Roma era imagem-fusão de formas artísticas que compunham o passado civilizacional da humanidade ocidental, já que conciliava o passado e o presente. Roma era uma cidade-relíquia. Nas palavras de Abbott, era plena de estilos e personalidades. Era, a seu ver, lugar onde natureza e espírito harmonizavam-se. Assim, sua admiração pela cidade extrapolava todas as suas expectativas em relação à sua visão sobre o que fora o Clássico. Escreve Jonathas sobre Roma (Galvão, 2007: 504):

Vi o soberbo castelo de Sant'Angelo, e passei à basílica de São Pedro. Vista mais nobre não pode haver, as belas fontes, as colunatas de rico e antigo mármore, ágata e pórfiro, o mosaico mais delicado exato, as estátuas colossais de bronze e mármore, o altar de pontífices, tudo imortalizado por gênios também imortais; em suma, é escusado tentar uma descrição quando essa força será pobre [...] apesar de estar ali por quatro horas esbugalhando o olho, não vi ainda a vigésima parte. [...] subi o soberbo capitólio e parei diante da estátua equestre de Marco Aurélio, menos para examinar essa soberba relíquia que para refletir que meus pés profanavam terreno sagrado. Quantos heróis endeusados ali receberam os seus louros? Quantos monarcas cativos ali aumentaram o triunfo do vencedor! [...] Eu ouço os quatro milhões de romanos enviar aos céus os seus ardentes votos, estou vendo as mães entregarem seus filhos, suas joias para a salvação da pátria; César, Bruto, Régulo e mil outros, eu os vejo e estou convosco no capitólio. Ah! minha alma não cabe no seu cárcere estreito, o coração me bate forte e as lágrimas me impedem de ver o que me rodeia [...] 
Tais descrições nos remetem às análises de Georg Simmel em que o autor anota, em I898, ou seja, 68 anos após a ida de Jonathas a Roma, impressões muito semelhantes às de Jonathas. Diz Simmel (20II: I5): "Aqui gerações incontáveis criaram e constituíram ao lado uma das outras e por cima uma das outras, cada uma delas sem se importar minimamente ou mesmo, a maior parte das vezes, sem compreender minimamente o que encontrava já feito, entregue exclusivamente às necessidades do presente e ao gosto ou ao capricho da sua época".

Abbott e Simmel, ainda que em tempos muito distintos, parecem dividir os mesmos sentimentos e visões sobre Roma. Para ambos, Roma unia a distância entre as épocas, os estilos, as personalidades, os conteúdos vitais que deixaram suas marcas na cidade como em nenhum outro lugar no mundo e, no entanto, entrelaçadas numa unidade, harmonia e afinidade como em nenhum outro lugar do mundo. As sensações fragmentárias e isoladas de Abbott sobre a cidade revelam sua fruição estética, que parece consistir em encontrar ou criar uma unidade na massa caótica das impressões e ideias que repousa na historicidade, no passado clássico. Roma produz o efeito de uma obra de arte da mais elevada ordem na visão de Abbott. A mesma visão também teve Georg Simmel (20II: I6) em sua reflexão estética sobre a cidade. Podemos afirmar que a individualidade de Jonathas é parte de um hábito de época, o qual, segundo o historiador da arte Ernst Gombrich (1994), contrário à afirmação de uma história "autônoma" da arte, toma a cultura em um sentido quase antropológico quando diz: "O que aproxima homens, mitos e obras de arte é, de uma parte, seu nascimento, sua transmissão em contextos culturais e sociais específicos [...] que possam ser explicados por uma análise de contexto $[\ldots] "$.

Ao deixar Roma, Jonathas anota em seu Diário (Galvão, 2007: 457): “[...] Oh! Verdadeira pátria de deuses e heróis, com que saudade deixo o teu sagrado solo! Deixo de ver e de tocar tuas estupendas ruínas, vestígios espantosos da tua antiga glória! Adeus!"

As ruínas despertavam em Abbott o mesmo sentimento que haviam despertado no esteta John Ruskin no mesmo século. As ruínas pareciam, para ambos, alegorias ou representações do que a edificação uma vez foi, mas deixou de ser, pois é também um monumento do presente, e por isso existe em correlação com a vivência das cidades e suas memórias. As ruínas apresentam-se como um fator de afirmações coletivas, individuais e nacionais a partir de sentimentos despertados por este "morto" que luta por sobrevivência e vida na sociedade a que pertence (Ruskin, I989).

No entanto, relatos como os de Abbott sobre Roma nos remetem também às narrativas dos viajantes do Grand Tour, fenômeno social que Valéria Salgueiro (2002: 30I) afirma ter sido típico da cultura europeia anterior ao mundo moderno sob o capitalismo. Tais viagens foram realizadas por pensa- 
dores como Goethe (I999), Horace Walpole e Thomas Gray, entre tantos outros estetas, intelectuais, filósofos, artistas, viajantes cujas proveniências eram primordialmente a Inglaterra, a França e a Alemanha. Todos viajavam até Roma declaradamente em busca de edificação pessoal e do estudo da cultura dos antigos. O verdadeiro Grand Tour envolvia, além de uma viagem a Paris, um circuito pelas principais cidades italianas - Roma, Florença e Nápoles (Salgueiro, 2002: 304).

A realização do Grand Tour transformou Jonathas em um grand tourist, conforme era nominado o viajante amante da cultura dos antigos e de seus monumentos. As motivações dos grand tourists beiravam a obsessão e uma inclinação inusitada para contemplar paisagens, amplas vistas panorâmicas, compostas segundo um idioma permeado por valores estéticos sublimes. Jonathas anota em sua viagem à cidade de Portici (Galvão, 2007: 463):

[...] quantos objetos raros me cercam por toda parte. O golfo de Nápoles, as inumeráveis vilas e povoações, o castelo de Sant'Élmo e o Vesúvio, o lago tranquilo de Agnano, a fumegante montanha, [...] os banhos quentes ao pé dela [...] em suma um panorama completamente encantador.

A aquisição de objetos o levou a viajar no tempo, a retornar à essência do Mundo Clássico, o que, por outro lado, parecia ser um encontro com seu passado, um encontro consigo mesmo, parecendo construir-se uma relação de simetria entre o passado e o presente na construção da individualidade de Abbott (Galvão, 2007: 503): “[...] Hoje comprei uma lâmpada romana e um lacrimatório". Os objetos representavam ideias e, para ele, eram verdadeiras obras de arte, a partir da noção moderna, tal como foi descrita por Norbert Elias (1995): eram singularidades. Os movimentos de viajar e de adquirir e colecionar objetos, segundo Elias, relacionam-se ao processo de exibir coisas ausentes do passado do mundo civilizado. Viajar é formação que sustenta e sintetiza um amplo movimento individual para o social e vice-versa, em uma aparência de leva e traz. "As pessoas colecionam para se civilizar" (Elias, I995: 85). E é nas viagens que, segundo Walter Benjamin (1982: 103), ocorrem as compras mais memoráveis, pois "colecionadores são pessoas de instinto prático; quando conquistam uma cidade desconhecida, sua experiência lhes mostra que a menor loja de antiguidades pode significar uma fortaleza".

\section{O RETORNO À BAHIA E A CONSTRUÇÃo DA GALERIA ABBOTT}

Em I832, Jonathas retornou à Bahia trazendo tudo o que adquirira nos dois anos na Europa. Havia constituído uma coleção que, ao longo dos anos, conformou a Galeria Abbott. Contudo, José Antônio do Prado Valladares, diretor do Museu do Estado da Bahia entre I939 e I942, professor de estética da Universidade da Bahia e autor de A Galeria Abbott, primeira pinacoteca da Bahia, 
monografia apresentada ao Io Congresso de História da Bahia em março de I949, diz ser a Galeria Abbott, como um todo, extremamente desigual, eclética, sem uma unidade de obras, objetos, temáticas, artistas e/ou linguagem poética, pois é composta de obras e artistas provenientes de distintas linguagens pictóricas, cujas temáticas também são extremamente ecléticas - incluindo a representação dos principais artistas da Escola Baiana de Pintura. Contudo, ressaltamos que o ecletismo das coleções no século XIX eram uma especificidade do colecionismo na época. A variedade e a heterogeneidade que regem uma coleção são justificadas pela lógica que o colecionador lhe outorga. Para Abbott, os objetos (fossem obras de arte ou objetos "quaisquer") tinham caráter universal e didático com atuação na consciência presente. $\mathrm{Na}$ compreensão de Abbott, colecionar definia-se como um ato de juntar coisas que possuem propriedades ou características comuns que servem para conhecer o mundo. Portanto, é a partir desta compreensão que podemos entender a razão do ecletismo de sua coleção: ela é heterogênea porque é composta por diversos padrões artísticos e culturais compatíveis aos modelos perceptivos condicionados pela relação do indivíduo (Abbott) com suas referências memoriais e cotidianas, fatores que levaram à formação de uma prática social que se configurou no prazer estético individual, ou gosto de Abbott.

Podemos, ainda, entender culturalmente o ecletismo da Galeria Abbott se a inscrevermos no cotidiano da sociedade baiana da primeira metade do século XIX. Suzana Alice Silva Pereira, em "A pintura baiana na transição do Barroco ao Neoclássico" (s/d), aponta para as muitas mentalidades na Salvador oitocentista; ou seja, havia uma não linearidade histórica, quer nas posturas coletivas, quer nas atitudes e nos discursos individuais, quer na expressão figurativa. Em se tratando da iconografia que, até então, era exclusivamente barroca, no decorrer do século XIX, outros modelos passaram a ser adotados, como o neoclássico, configurando-se, então, uma produção artística de transição, híbrida, com obras associadas a ambos os modelos, e pintores exercitando-se em diferentes temáticas e tratamentos formais, o que resultou numa produção artística eclética. Assim, renovação e permanência estabeleceram um diálogo evidente na Galeria Abbott.

Analisando a questão do ponto de vista de um mercado de arte inexistente na Bahia da segunda metade do século XIX, a clientela representada quase exclusivamente pelas instituições religiosas diversifica-se, e outros segmentos sociais passam a fazer parte do mercado, fazendo surgir a figura do colecionador particular, como Jonathas Abbott e outros de seu tempo. Segundo o historiador Paulo Knauss Mendonça (s/d: 2), a prática de colecionar de Jonathas Abbott foi extremamente importante, pois trouxe desdobramentos para os artistas baianos da época: "Ao integrar o movimento de criação da Sociedade de Belas Artes, o médico anglo-baiano e amante das artes participou do processo de liberalização das artes na Bahia, promovendo a carrei- 
ra de artista como profissional autônomo no mercado livre, distante das restrições impostas pelas antigas corporações de ofício que dominavam o campo dos artesãos".

Seguindo essa linha interpretativa, podemos afirmar que a Galeria Abbott e a própria individualidade de Jonathas encarnam uma trajetória de mediação sociocultural que, segundo Gilberto Velho (2010), oferece uma plasticidade que se manifesta na capacidade de transitar e desempenhar o papel de mediadores entre distintos grupos e códigos sociais. Jonathas Abbott foi um mediador, um intérprete de seu tempo e um reinventor de si próprio, ao mesmo tempo em que ofereceu pluralidade cultural à arte baiana de meados do século XIX, quando, por exemplo, reuniu em sua coleção objetos, obras e artistas europeus à produção artística baiana (brasileira). Abbott foi, sobretudo, um agente de mudança quando, através de seu cosmopolitismo objetivo e subjetivo aportou informações, novos costumes, hábitos, bens e aspirações à sociedade de seu tempo.

Abbott construiu um museu particular, não exclusivamente voltado para uma corrente artística; ao contrário, construiu uma coleção cuja particularidade era o agrupamento heterogêneo de objetos em que o homogêneo é o valor histórico. Essa pedagogia dos objetos é que proporciona a lógica variada da coleção: o objeto tem algo para ensinar do passado, é suporte para o êxito de um ato pedagógico que seria a constituição de um futuro museu campo para a recriação da história e da tradição.

A amizade de Jonathas Abbott com os membros fundadores da Sociedade de Belas Artes, com os quais compartia a vocação pelo colecionismo, manifesta-se na participação conjunta no que pode ser definido como um programa cultural e criação de canais oficiais de instituições do saber na Salvador do século XIX. Ao fundar a Sociedade de Belas Artes, vemos que este grupo de homens das letras, das ciências, das artes, intelectuais e profissionais liberais tinha o objetivo de despertar o gosto pelas manifestações artísticas, elevando moralmente a sociedade baiana, a classe dos artistas e, ainda, dando a oportunidade aos artistas da época de apresentar seus trabalhos em exposições anuais. Mais tarde, a Sociedade de Belas Artes passou a convidar artistas que quisessem vender quadros, esboços, desenhos, gravuras ou quais quer outras peças de arte. Esse grupo de intelectuais, amantes das artes, criou espaços culturais de indiscutida importância do ponto de vista institucional, os quais se tornaram os primeiros museus da cidade.

$\mathrm{Na}$ época, não havia nenhum museu em Salvador. Nem histórico, nem de artes. Tudo estava por fazer, e o que existia era um grupo de homens dispostos a enfrentar a tarefa. Desse grupo fez parte o inglês Jonathas Abbott, que levou a cabo a progressiva institucionalização do campo artístico e intelectual. Sua figura foi progressivamente reconhecida na sociedade de seu tempo como fundadora e impulsionadora das iniciativas de construção de museus na cida- 
de. Por outro lado, essas novas práticas, como o colecionismo e a constituição da Sociedade de Belas Artes, foram acompanhadas por um paulatino ingresso de obras de arte do Velho Continente no Novo Mundo. Neste rico e complexo processo formaram-se as primeiras coleções de arte com que contaram a Bahia e o Brasil. O colecionismo artístico se integrou a um projeto político institucional, cuja ideologia era edificar a nação por meio da educação de seus cidadãos mediante a esfera artística. Essas iniciativas também podem ser vistas como manifestações de uma prática em que se reflete a relação entre os âmbitos público e privado. De um lado, a atuação de um grupo, dentro da elite, que toma a direção enquanto política cultural; de outro, a atuação do poder político na organização de uma incipiente política cultural.

Os indivíduos envolvidos na criação da Sociedade de Belas Artes foram os que contribuíram com seu esforço para o progresso material da cidade, foram os que aportaram suas próprias coleções nos projetos dos museus. A participação deles como homens da cultura, como professores e colecionadores, os fez, também, membros de uma geração e de um grupo social que tomara a seu cargo o desenvolvimento cultural e institucional da cidade como modo de consolidação de sua posição hegemônica dentro da sociedade, já que viam a si mesmos com um papel pedagógico a cumprir. Esse grupo era conformado por homens que, como Jonathas Abbott, combinavam múltipla inserção institucional com a atividade política, a docência e a sensibilidade artística, transformando tais atividades em numerosas associações, comissões, entidades de caráter cultural, filantrópico ou educativo.

Portanto, a afeição de Abbott pelo colecionismo artístico e histórico foi fundamental na construção da individualidade do colecionador Jonathas Abbott. Destacamos, ainda, que tanto a construção de sua individualidade quanto a formação de sua coleção fizeram parte do mesmo processo: o de sua ascensão social. Nesse processo, o Clássico, com o qual Jonathas entrou em contato em seu Grand Tour, tornou-se a essência estética de sua coleção. Por outro lado, a primeira viagem foi, ao mesmo tempo, núcleo de sua coleção e campo de aperfeiçoamento profissional. A viagem converteu-se em prática de diferenciação social, que lhe garantiu o pertencimento a certo grupo de notáveis ao mesmo tempo em que constituiu em elemento de distinção na sociedade baiana de seu tempo.

Jonathas Abbott viajou mais uma vez à Europa, entre I852 e I853, onde adquiriu mais obras. Foi importante agente no comércio de artes na Bahia, tornando-se comprador compulsivo de obras nacionais e internacionais. Morreu em I868, aos 7I anos, em casa, no Caminho Novo do Gravatá (atual rua 28 de Setembro, no Pelourinho), com a maior coleção de obras de artes do Império, segundo Morais Filho (Galvão, 2007: 350). Em abril de I869, o governo da Bahia adquiriu parte de suas obras, as quais foram doadas ao Liceu Provincial. Em I93I, as obras foram transferidas para a pinacoteca do Estado da Bahia. 
Finalmente, em 1938 a Coleção Abbott foi enviada ao Museu de Artes da Bahia, recém-inaugurado no antigo palacete Góes Calmon, no Corredor da Vitória, Salvador. Em 30 de junho de 2000, a diretora do museu, Sylvia Athayde, fez uma relação completa do que restava, e, de um total de I6o obras, permanecem 37 telas de artistas baianos e demais brasileiros, e I23 de artistas estrangeiros (todas não identificadas). A Galeria Abbott permanece até hoje como o núcleo da coleção do Museu de Artes da Bahia.

Recebido em 09/10/20I2 | Aprovado em I2/02/20I4

Cláudia de Oliveira é professora adjunta da Escola de Belas Artes da Universidade Federal do Rio de Janeiro (EBA-UFRJ). Suas áreas de interesse são arte e gênero, arte e moda, e colecionismo. Publicou 0 moderno em revistas.

Representações do Rio de Janeiro de I890 a I930 (2010), e vários artigos em revistas nacionais e estrangeiras. 


\section{NOTAS}

I Fernando Abbot Galvão era descendente direto de Jonathas Abbott (por conta do affair entre Jonathas Abbott e Cecilia Walters). Foi diplomata e escritor. Fernando publicou o diário na íntegra - tal como havia recebido como herança - e fez uma pesquisa de io anos para as notas de rodapé (mais de 500). Escreveu uma pequena biografia do trisavô, que constitui a segunda parte do diário, com muitas informações sobre a vida de Jonathas. Faleceu em Natal onde vivia - em abril de 2009. Deixou viúva Sonia Bezerra Galvão e três filhos.

2 Por intenção subjetiva e objetiva, referimo-nos aos conceitos elaborados por Georg Simmel, cultura objetiva e cultura subjetiva. A cultura subjetiva é entendida como sendo formada na troca interacional feita por indivíduos possuidores de um quantum de liberdade, o que permite o aumento da diferenciação entre cada um deles e nos grupos e arranjos sociais por eles organizados, complexificando a relação e a vida na cidade. Já a cultura objetiva se apresenta socialmente como resultado das trocas subjetivas dos indivíduos, em um jogo interacional, compondo interesses e divergências, tendências, estilos e modos de viver. Ver Simmel (I998).

3 Capital cultural, econômico e social são conceitos desenvolvidos por Pierre Bourdieu. O conceito de capital apoiase em bases teóricas distintas para falar das vantagens culturais e sociais mobilizadas pelos indivíduos e que geralmente os conduzem a um nível socioeconômico mais elevado.

4 Em, "Eu vi o mundo...", a autora, Maria de Lourdes Eleutério, discute a coleção de Oliveira Lima e afirma que "os relatos ampliam a inteligibilidade acerca das relações entre os produtores de arte e o colecionador na constituição do acervo" (2004: IO).

5 O uso da expressão "Mundo Clássico" é tomado aqui para falar do encontro de nosso protagonista com as relíquias deixadas pela Antiguidade Clássica - por Grécia e por Roma - entre os séculos V a.C. e VII d.C., na viagem por ele realizada, entre I830 e I832, à Europa. 
6 Antônio Joaquim Franco Velasco (Salvador, I780-I833). Pintor, professor. Autor de diversos retratos e pinturas decorativas para igrejas de Salvador. No início da década de I8Io, realizou trabalhos para a Matriz de Santana; por volta de I8I3, produziu pinturas para o teto da nave; e, em I8I4, foi incumbido de fazer o painel da pia batismal. Entre I8I8 e I820, executou a pintura do forro e de sete painéis retratando os passos da Paixão de Cristo para os altares da Igreja do Senhor do Bonfim, além do douramento da capela-mor, de altares, tribunas, púlpito e coro. É também autor da pintura do forro da capela-mor da Igreja Matriz do Santíssimo Sacramento de Itaparica. Em I82I, foi nomeado docente substituto da cadeira pública de desenho de Salvador, possivelmente por incentivo de D. João VI (I767-I826), em agradecimento aos dois quadros que lhe foram presenteados. Sobre essas informações ver Alves (I976: 210).

7 D. Pedro II assistiu a uma das aulas de anatomia de Jonathas Abbott na Escola de Medicina e se impressionou com seu conhecimento. Sobre essa discussão, ver Galvão (2007: 354).

\section{REFERÊNCIAS BIBLIOGRÁFICAS}

Alves, Marieta. (1976). Dicionário de artistas e artífices na Bahia. Apresentação de Godofredo Filho. Salvador: Ed. UFBA.

Benjamin, Walter. (1987). Desempacotando minha biblioteca. In: Obras escolhidas II: rua de mão única. São Paulo: Brasiliense.

Benjamin, Walter. (I982). O colecionador. In: Passagens. Belo Horizonte/São Paulo: Ed. UFMG/Imprensa Oficial do Estado de São Paulo.

Bourdieu, Pierre. (2008). A distinção: crítica social do julgamento. São Paulo/ Porto Alegre: Ed. Unesp/Zouk.

Bourdieu, Pierre. (I996). A ilusão biográfica. In: Amado, Janaína \& Ferreira, Marieta de Moraes (orgs.). Usos e abusos da história oral. Rio de Janeiro: Ed. FGV, p. I83-I9I.

Boyer, Christine. (1998). The city of collective memory: Its historical imagery and architectural entertainments. Cambridge: MIT Press. 
Eleutério, Maria de Lourdes. Eu vi o mundo... ele começava no Recife. Remate de males, 24, 2004. Disponível em: <http://revistas.iel.unicamp.br/index.php/remate/article/ viewFile/32II/2690>. Acesso em I8 fev 2014.

Elias, Norbert. (1995). Mozart: sociologia de um gênio. Rio de Janeiro: Zahar.

Flexor, Maria Helena Ochi. (s/d). Raízes da arte moderna Bahia/Brasil. Artelogie, I. Disponível em: <http://cral.in2p3. fr/artelogie/spip.php?article75>. Acesso em I8 fev 2014.

Freyre, Gilberto. (2000). Ingleses no Brasil: aspectos da influência britânica sobre a vida, a paisagem e a cultura do Brasil. 3. ed. Prefácio de João Cabral de Mello Neto. Rio de Janeiro: Topbooks.

Galvão, Fernando Abbott. (2007). O diário de Jonathas Abbott. Prefácio de Rubens Ricupero. Rio de Janeiro: Francisco Alves.

Goethe, Johann Wolfgang von. (I999). Viagem à Itália, I786I788. São Paulo: Companhia das Letras.

Gombrich, Ernst Hans. (I994). Para uma história cultural. Lisboa: Gradiva.

Hansen, João Adolfo. (2003). Freiráticos na sátira lusobrasileira do século XVII. Revista da USP, 57, pp. 68-85.

Mendonça, Paulo Knauss de. (s/d). O cavalete e a paleta: Arte de colecionar no Brasil. Labhoi. Disponível em: <http:// www.historia.uff.br/labhoi/files/Mayo7HQ6_MUcT_cavalete_paleta.pdf>. Acesso em I8 fev 2014.

Miranda, Ana. (I998). Que seja em segredo. Rio de Janeiro: Dantes.

Neves, Maria Helena França. (1994). Jonathas Abbott: um lugar de memória. Trabalho final da disciplina História da Bahia no século XIX, Mestrado em Artes. Salvador, Escola de Belas Artes, Universidade Federal da Bahia (EBA-UFBA). Panofsky, Erwin. (I99I). A história da arte como uma disciplina humanista. In: Significado das artes visuais. São Paulo: Perspectiva, p. I9-46.

Pereira, Suzana Alice Silva. (s/d). A pintura baiana na transição do barroco ao neoclássico. Cadernos do MAV-EBAUFBA. Disponível em: <www.portalseer.ufba.br>. Acesso em I8 fev. 2014. 
Ruskin, John. (1989). The seven lamps of architecture. Londres: Dover.

Salgueiro, Valéria. (2002). Grand Tour: uma contribuição à história do viajar por prazer e por amor. Revista Brasileira de História, 22/44, p. 289-310.

Simmel, Georg. (20II). Roma: uma análise estética. In: Fortuna, Carlos (org.). Simmel: a estética e a cidade. São Paulo/ Coimbra: Annablume/Imprensa da Universidade de Coimbra (Col. Olhares), p. 23-30.

Simmel, Georg (1998). A divisão do trabalho como causa da diferenciação da cultura subjetiva e objetiva. In: Souza, Jesse \& Oelze, Berthold (orgs.). Simmel e a modernidade. Brasilia: Ed. UnB, p.4I-76.

Valladares, José. (I95I). A Galeria Abbott: primeira pinacoteca da Bahia. Salvador: Secretaria da Educação/Museu do Estado.

Velho, Gilberto. (2010). Metrópole, cosmopolitismo e mediação. Horizontes Antropológicos, I6/33, jan./jun., p. I5-23. 


\section{JONATHAS ABBOTT: INDIVIDUALIDADE E COLECIONISMO NA BAHIA NO SÉCULO XIX}

O artigo discute o contexto de formação da principal coleção de artes que compõe o atual Museu de Artes da Bahia, a coleção Jonathas Abbott, tomando como fonte de pesquisa um relato autobiográfico: o Diário de viagem do autor à Europa, entre I830-1832. Esta análise propõe uma reflexão sobre a construção da individualidade do colecionador Jonathas Abbott, entre I8I6 e I887 - período que corresponde a sua trajetória de vida no Brasil - buscando compreender a essência estética da coleção e a natureza do gosto de Abbot. Nossa hipótese é a de que a construção da individualidade de Abbot, a formação de seu gosto e a natureza estética de sua coleção foram elementos conformadores do espírito da Galeria Abbott - como um todo.

\section{JONATHAS ABBOTT: INDIVIDUALITY AND COLLECTING IN BAHIA IN THE NINETEENTH CENTURY}

Abstract

The article discusses the context of the formation of the main art collection of the current Art Museum of Bahia, Jonathas Abbott Collection, examining the autobiographical narrative of Abbott's travel diary, which was written during his travel to Europe between 1830 and I832. By investigating the construction of the individuality of the collector Jonathas Abbott during his time in Brazil (I816-1887) it aims to understand the aesthetic basis of Abbott's collection and the nature of his taste. It is argued that Abbott's individuality, the formation of his taste, and the aesthetic nature of his collection constituted defining elements of the spirit of Abbott Gallery as a whole.
Palavras-chave

Individualidade;

Arte;

Colecionismo;

Bahia;

Século XIX.

\section{Keywords}

Individuality;

Art;

Collecting;

Bahia;

Nineteenth Century. 